Antimicrobial prophylaxis to prevent surgical site infection in Adolescent

Idiopathic scoliosis patients undergoing posterior spinal fusion- 2 doses Vs

antibiotics till drain removal

\title{
Authors:
}

Vijay H D Kamath", MS (ortho),FNBE

Jason Pui Yin Cheung" (Dual first author), MBBS, MMedSc, FRCSEd (ortho), FHKCOS, FHKAM (ortho)

Kin Cheung Mak", MBBS, FRCSEd (ortho), FHKCOS, FHKAM (ortho)

Yat Wa Wong", MBBS, FRCSEd (ortho), FHKCOS, FHKAM (ortho)

Wai Yuen Cheung", MBBS, FRCSEd (ortho), FHKCOS, FHKAM (ortho)

Keith Dip Kei Luk ${ }^{\#}$ MBBS, MCh(orth), FRCS(Edin), FRCS(Glas), FRACS, FHKCOS, FHKAM (ortho)

Kenneth Man Chee Cheung ${ }^{\#}$, MBBS (London), MD (HK), FRCS(England), FHKCOS, FHKAM (ortho)

\#Affiliation: Department of Orthopaedics and Traumatology, The University of Hong Kong

Correspondence: Jason Pui Yin Cheung

Clinical Assistant Professor

Department of Orthopaedics and Traumatology 
The University of Hong Kong

$5^{\text {th }}$ Floor, Professorial Block

Queen Mary Hospital

Pokfulam, Hong Kong

Tel: (+852) 2255-4581

Fax (+852) 2817-4392

Email: cheungjp@hku.hk

Disclosure: The authors have no disclosures to report. 


\section{Antimicrobial prophylaxis to prevent surgical site infection in Adolescent Idiopathic scoliosis patients undergoing posterior spinal fusion- 2 doses versus} antibiotics till drain removal

1

\section{ABSTRACT}

3 Purpose: There is much variation in the choice, timing and duration of antimicrobial prophylaxis for preventing surgical site infections (SSI) but no guideline exists for scoliosis surgery. The aim of study was to compare the efficacy of two antimicrobial prophylaxis (AMP) protocols with cephazolin in preventing SSI in adolescent idiopathic scoliosis (AIS).

Methods: A retrospective comparative analysis of two post-operative AMP protocols (two postoperative doses versus continued antibiotics till drain removal) was performed. Patient characteristics, pre-operative, intra- and post-operative risk factors for infection, drain use, generic drug name and number of doses administered were recorded from 226 patients with AIS who had undergone posterior spinal fusion. Details of superficial or deep SSI and wound healing aberrations, and serious adverse events were recorded. Analysis was performed to evaluate differences in the pre-, intra- and post-operative variables between the two groups.

Results: 155 patients received 2 postoperative doses of AMP and 71 patients had antibiotics till drain removal. The average follow-up was 43 months. The overall rate of SSI was $1.7 \%$ for the spine wound and $1.3 \%$ for the iliac crest wound. $1.9 \%$ of patients with 2 doses of 
1 AMP and $1.4 \%$ of patients with antibiotics till drain removal had SSI. No adverse reactions 2 attributable to cephazolin were observed.

3 Conclusions: This is the first study on the AMP protocol in scoliosis surgery for SSI 4 prevention. Results suggest that two doses of AMP are as effective as continued antimicrobial 5 use until drain removal. Cephazolin appears to be effective and safe for prophylaxis.

6

7 Key Words: Antimicrobial prophylaxis; adolescent idiopathic scoliosis; posterior spinal 8 fusion 


\section{INTRODUCTION}

Surgical site infection (SSI) after spinal fusion results in increased patient morbidity, prolonged hospital stay, long-term administration of antimicrobial drugs, multiple surgeries, hardware removal, pseudarthrosis and added health-care cost.[1-5] The prevalence of postoperative SSI increases with the complexity of the procedure and is reported to range from $<1 \%$ for discectomy[6,7] to as high as $10 \%$ for instrumentation surgery.[8,9] In adolescent idiopathic scoliosis (AIS) surgery, the reported rate of infection is between $0.71 \%$ and 6.9\%.[10-15]

Pre-operative antimicrobial prophylaxis (AMP) is one of the keys to reduce the rate of SSI.[6,16-18] There is however, a great deal of variation regarding the choice of prophylactic antibiotics, optimal timing and duration of treatment.[19,20] Surgical AMP refers to a very brief course of antimicrobials initiated just before surgery.[21-24] It is a critically timed adjunct used to reduce the microbial burden of the intra-operative wound to a level that cannot overwhelm host defences, but not to sterilize tissues. The initial dose of antimicrobial is timed so that bactericidal concentration is established in serum and tissues by the time of skin incision with re-dosing to maintain therapeutic level of the drug in both serum and tissues throughout the operation and until a few hours after wound closure.[25] AMP does not pertain to prevention of SSI caused by post-operative contamination.[24] The fear of SSI and its attendant complications prompts many surgeons to continue antibiotics in the postoperative period ranging for 24-48 hours[20,23] and often until drain removal. There is growing evidence in spine literature that this practice is unwarranted. AMP plays a vital role for preventing infection but indiscriminate and prolonged use of these drugs may expose patients to adverse drug reactions and encourage the emergence of resistant bacteria.[22,26,27] Hence an antimicrobial prophylaxis protocol which is safe, efficacious, requires the least number of doses to be administered and cost-effective is ideal. 
The 'Center for Disease Control (CDC) guideline for the prevention of SSI'[25] has made recommendations regarding the possible choice of prophylaxis antibiotics, i.e. an antimicrobial that is safe, inexpensive and bactericidal with an in-vivo spectrum that covers the most probable intra-operative contaminants. It also recommends the timing of infusion of the first dose and drug duration to establish and maintain therapeutic serum and tissue levels throughout surgery. There is however a paucity of literature regarding the application of this guideline in spine surgery[20,26,28] and none with regards to scoliosis surgery.

The main aim of study is to document the efficacy of our present AMP protocol in preventing SSI and to compare it to our previous protocol of continued post-operative antimicrobial drug administration until drain removal for AIS surgery. Additional aims include evaluation of whether cephazolin (first-generation cephalosporin) is safe and efficacious in preventing SSI and identifying its risk factors.

\section{METHODS}

This was a comparative analysis of two consecutive series of patients (1993-2004, 2005-2011) with AIS who had undergone posterior spinal fusion. Ethics approval was obtained from a local institutional review board. Patient characteristics included age, sex, and body mass index (BMI). Pre-operative risk factors for SSI including history of smoking, preexisting medical illness especially poor glycemic control, recent infection or persisting focus of infection and nutritional status in terms of total protein, albumin and globulin levels were recorded. Intra-operative and post-operative risk factors including estimated intra-operative blood loss, duration of surgery, number of vertebral levels fused and anchor points, postoperative drain collection and its duration were recorded. The generic name and number of doses of the antimicrobial administered was noted. For patients receiving AMP according to 
1 the CDC criteria, two additional doses were received postoperatively. For patients who

2 received antimicrobials until drain removal, the number of days the drug was administered was recorded. For these patients, three doses of cephazolin were given per postoperative day (dosing every 8 hours). Serious adverse events including drug toxicity, allergic reaction or anaphylactic shock and antimicrobial associated colitis were recorded.

A superficial infection was diagnosed with clinical signs of infection involving the skin, subcutaneous tissue, or muscle located above the fascial layer and accompanied by purulent drainage above the fascial layer and positive wound culture.[26] A deep infection was diagnosed when infection was found to involve tissue below the fascia. For each patient with SSI, the organism isolated, its antimicrobial sensitivity and subsequent management was recorded. Wound healing aberrations including delay in wound healing, wound dehiscence, hematoma or prolonged culture negative serous discharge, stitch abscess in the spine as well as in the iliac crest wound were noted. The post-operative follow-up notes were scrutinized for any late wound healing complications including infection after the skin healed and imaging confirmed pseudarthrosis.

In our institution, patients were admitted the day prior to surgery and were screened for any active infective focus. In the presence of an active infection, surgery was postponed until the infection was eradicated. Necessary interventions were undertaken to optimize the patient's preoperative general health status. All patients bathed the night prior to surgery, no shaving was performed and skin preparation was standardized with providone-iodine scrub. A standardized surgical procedure of autogenous bone grafting, implant insertion, deformity correction and fusion was performed in a laminar airflow theatre. Three independent spine specialists were involved in all the operations. All patients received autogenous blood transfusion (stored 1 month prior to operation). No cell saver was used. Autogenous bone graft used for fusion was harvested from the posterior iliac crest immediately prior to the 
1 main spinal incision. No allograft bone or bone substitutes were used in any of the cases. The

2 surgical sites were irrigated with normal saline after completion of surgical dissection,

3 insertion of all anchors, after rod insertion and prior to wound closure. Standardized closure

4 was performed with watertight closure of fascia and subcutaneous with continuous vicryl

5 sutures, and buried subcuticular monocryl sutures. Single suction drain was routinely placed

6 in the spinal wound and removed when the collection was $<50 \mathrm{ml}$ over a 24-hour period. No

7 drains were placed in the iliac crest wound. No topical antibiotics were used. All preparation

8 and surgical protocols were standardized between the three surgeons.

9 Cephazolin, a first-generation cephalosporin, administered at a dose of $20-30 \mathrm{mg} / \mathrm{kg}$ body weight was used as AMP. It was administered 30 minutes before skin incision and an additional dose administered intra-operatively every 4 hours to maintain therapeutic levels throughout surgery. Prior to 2005, antimicrobials were continued in the post-operative period until drain removal; however since then antimicrobials were only administered pre-incision with re-dosing intra-operatively when the procedure duration exceeds 4 hours. This practice was changed in 2005 following the advice of the infection control unit at our institution.

Statistical analysis was performed using SPSS version 19. Analysis of variance variables between the two groups. Pearson's chi-square test and Mann-Whitney tests were used for outcome analysis. Fisher's Exact Test was employed when data points were less than or equal to 5 . A p-value of $<0.05$ was considered significant. 
226 patients with average 43 months follow-up (range: 18-104 months) were included in the study, of which 155 (68.6\%) patients (group A) received 2 doses of postoperative AMP and 71 (31.4\%) patients (group B) received antimicrobials until drain removal (range: 3-5 days). No significant differences were observed between the two groups (Table 1) with respect to mean age, sex, BMI, smoking, pre-operative hemoglobin, nutritional status (total protein and albumin), scoliosis curve type, mean number of levels fused per patient, intraoperative transfusion, post-operative transfusion and duration of drain left in-situ. A significant difference was observed between the groups in terms of pre-operative globulin levels, type of instrumentation system, mean number of anchor points per patient, intraoperative and post-operative blood loss between the groups. Although there was approximately $150 \mathrm{ml}$ more blood loss intra-operatively for group A, interestingly group B had more intraoperative and postoperative transfusions. Patients in group A had lower preoperative globulin levels and more anchor points per patient as compared to group $\mathrm{B}$. The globulin levels however were in the normal range in both groups and hence this finding might not be clinically significant. Group B had fewer patients with all pedicle screw constructs as most of these patients were operated prior to popularization of all pedicle screw constructs (Table 2). 14 of 71 patients in Group B had a deep spine wound drain whilst all group A patients had a subcutaneous plane drain (due to a change in policy in drain usage) and this accounted for the difference in total drain output. Too few patients in Group B had deep spine wound drains to find any statistical significant differences in SSI. No statistical differences in all patient parameters and outcomes were found between the 3 operating surgeons.

For pre-existing medical problems, 14 patients had allergic rhinitis and or asthma, 2 had atopy, 3 had G6PD deficiency, 3 patients had thalassemia trait and 2 with thalassemia minor, 5 patients had cardiac valve anomalies, 2 patients were obese and 1 had recovered 
1 from leukemia. No patients had anemia or any active focus of infection. No patients had

2 diabetes or abnormal blood glucose prior to surgery.

The overall rate of SSI was $1.7 \%$ for the spine wound and $1.3 \%$ for the iliac crest wound. For the spine wound, 3 of 155 (1.9\%) patients in group A had SSI (1 superficial and 2 deep), while there was only 1 deep SSI (1.4\%) in group B ( $\mathrm{p}=1.0)$. For the iliac crest, two (1.3\%) patients in group A, and one (1.4\%) patient in group B had a superficial SSI ( $\mathrm{p}=1.0)$. The organisms cultured and the management of the infected patients was detailed in table 3. All the deep infections were managed with a single debridement and antibiotics given according to culture sensitivity reports and none required implant removal. Duration of use depended on clinical response and microbiologist consultation. The superficial infections were managed with appropriate antibiotics only. There were no late infections seen. Nine of 155 (5.8\%) patients in group A and seven of 71 (9.8\%) patients in group B had spine wound healing aberrations, but the difference was not significant $(\mathrm{p}=0.489)$. One of $155(0.6 \%)$ patients in group A and four of 71 (5.6\%) patients in group B had iliac crest wound healing aberrations, but the difference was also insignificant $(\mathrm{p}=0.059)$. None of these wound healing aberrations required further treatment besides observation. No adverse drug reactions or side effects attributable to cephazolin were observed.

\section{DISCUSSION}

This is the first study to compare the outcomes of two different AMP protocols. The overall rate of SSI in this study is $1.7 \%$ which is within the range of $0.71 \%$ to $6.9 \%$ as reported in literature.[10-15] In group A, the rate of spine wound SSI was 1.9\%, while in group B, the rate was $1.4 \%$. Statistically speaking, there were no significant differences in the prevalence of spine and iliac crest wound SSI. This implies that a short duration of AMP is 
1 equally effective in reducing the rate of SSI as compared to post-operative continuation of

2 AMP until drain removal. This also implies that cephazolin is an effective prophylactic

3 antimicrobial agent. Furthermore, no adverse drug events are observed which demonstrates

4 its safety.

The particularly low infection rate in this study can be contributed to the type of patients operated on. All the AIS patients in this study are healthy teenagers who generally do not have high risk for infections to begin with. Poor glycemic control or diabetes mellitus has been shown to increase the risk of SSI.[29] As expected, this is not a risk factor found in our patients.

Late infection after the surgical treatment of AIS is a concern. Its incidence ranges from $1.4 \%$ to $6.9 \%[13,30]$ and usually occurs at an average of 2 years after surgery. In our series, 201 patients were followed up for a minimum period of 24 months and no cases of late infection were found in either group. Our data suggests that a shorter duration of AMP does not predispose to an increased rate of late infection.

A secondary outcome was to compare the prevalence of wound healing aberrations even though they did not affect the overall clinical outcome. This was done to ensure that a change in antibiotic schedule did not lead to any difference in wound healing. Interestingly, despite a longer duration of antibiotic use in group B patients, a larger percentage of patients had spine and iliac crest wound aberrations. Although this result was still statistically insignificant, it suggested that a shorter antibiotic regimen did not negatively affect wound healing. It should be noted that these wound healing complications did not result in delayed suture removal or prolonged hospital stay.

The results of our study provide further evidence that short duration AMP is adequate even in extensive surgical procedures such as scoliosis correction that involves massive soft 
1 tissue dissection, bone decortication and a large amount of instrumentation. None of the

2 organisms isolated from group A patients were drug resistant, whereas 1 of 3 (33\%)

3 organisms isolated from group B patients (prolonged antibiotics) was methicillin-resistant

4 Staphylococcus Aureus (MRSA). The prevalence of antibiotic resistant organism in our study

5 is too low to comment on whether prolonged antibiotic use may lead to development of

6 antibiotic resistance. However the evidence from our study and literature[17,22,26,31] leads

7 us to believe that short duration AMP is effective and that prolonged drug administration

8 post-operatively should be avoided to reduce the emergence of drug resistant organisms.

9 Kanayama et al.[26] reported in their study that $83.3 \%$ of organisms isolated from patients

10 with SSI in the multiple-dose group were resistant strains of bacteria, whereas none in the

11 single-dose group were resistant. Unlike these studies, we do not see an increase in culture of resistant bacteria.

The choice of prophylactic antimicrobial drug is an important factor in preventing SSI.[27,32] The ideal antibiotic should be safe, inexpensive, and bactericidal with an in-vivo spectrum that covers the most probable intra-operative contaminants. For orthopedic surgery, microorganisms classically recovered from wound infections in patients with no pre-existing focus of infection include Staphylococcus aureus, S. epidermidis, S. lugdunensis and Propionibaterium acnes.[15,22,27,33-36] Because of the frequency of isolation of these organisms, $\beta$-lactams such as cephalosporins and penicillins are most often selected for AMP. Cephalosporins have been shown in studies to be effective against many gram-positive and gram-negative microorganisms.[37] They also share the features of demonstrated safety, acceptable pharmacokinetics, and a reasonable cost per dose.[21] In particular, cephazolin is widely used and generally viewed as the first choice antimicrobial drug for clean operations. Authors of trials in which cephazolin was compared with second- and third-generation cephalosporins have failed to show any difference in efficacy.[26,38,39] The results of our 
1 study combined with Rubinstein et al.[17], Takahashi et al.[20] and Kanayama et al.[26]

2 provide evidence for the use of cephazolin as the first-line prophylactic antimicrobial agent

3 for spinal surgery.

The current study has the drawbacks of having a small sample size. An adequately powered prospective randomized clinical trial would be ideal to verify our findings especially considering this is a study on AMP. However considering the low rate of infection in scoliosis surgeries (approximately 2-3\%) as pointed out by Dimick et al.[32], for a baseline infection rate of $2 \%$ it is necessary to enroll 2518 patients in each treatment group to detect a difference in SSI rates. Clearly, the magnitude of this number indicates that a multi-center clinical trial is required as we do not have over 5000 cases in our cohort to address this issue.[40] This is not only necessary for scoliosis patients but for all spine disorders as the current North American Spine Society guidelines provides only fair recommendations for antibiotic prophylaxis in spine surgery.[41] It should be cautioned that the external validity of the study may be limited for settings with increased resistance of S. epidermidis to $\beta$-lactam antibiotics, or hyper-endemic occurrence of MRSA. Another limitation is that the two groups include patients from two separate time periods and thus not as strong of a comparison as in a prospectively matched cohort. There are inherent differences in instrumentation (modern pedicle screw based and earlier hook based) and drain use (earlier deep placement beneath the thoracolumbar fascia and modern superficial placement). This may have an effect on the post-operative wound behaviour but interestingly there is no significant increase in operative time or postoperative increase in drain output for hook instrumentation nor deep drains. Although all three surgeons are experienced, the lack of differences in duration of surgery may reflect the difficulties of engaging hook anchors to rods in earlier patients.

This is the first and largest study on AMP protocol in scoliosis surgery. Despite the reported limitations, results suggest that short duration AMP with cephazolin is safe, effective 
1 and cost-effective in scoliosis surgery. The rates of infection are comparable to that reported

2 in literature and there is no increased predisposition to late infection. Reduced number of

3 doses of antimicrobials may reduce health care cost. Reduced adverse effects, negating need

4 for intravenous access, reduced workload for the nursing staff and possibly prevention of

5 antibiotic resistance are other potential advantages. This study is a platform for future

6 prospective multicenter-randomized-controlled-trials to further establish this protocol for

7 scoliosis surgery.

9 References

10 1. Benson ER, Thomson JD, Smith BG, Banta JV (1998) Results and morbidity in a consecutive series of patients undergoing spinal fusion for neuromuscular scoliosis. Spine (Phila Pa 1976) 23:2308-17; discussion 18.

2. Calderone RR, Garland DE, Capen DA, Oster H (1996) Cost of medical care for postoperative spinal infections. Orthop Clin North Am 27:171-82.

3. Glazer PA, Hu SS (1996) Pediatric spinal infections. Orthop Clin North Am 27:11123.

4. Milstone AM, Maragakis LL, Townsend T, Speck K, Sponseller P, Song X, Perl TM (2008) Timing of preoperative antibiotic prophylaxis: a modifiable risk factor for deep surgical site infections after pediatric spinal fusion. Pediatr Infect Dis J 27:7048.

5. Whitehouse JD, Friedman ND, Kirkland KB, Richardson WJ, Sexton DJ (2002) The impact of surgical-site infections following orthopedic surgery at a community hospital and a university hospital: adverse quality of life, excess length of stay, and extra cost. Infect Control Hosp Epidemiol 23:183-9. 
16 Horwitz NH, Curtin JA (1975) Prophylactic antibiotics and wound infections following laminectomy for lumber disc herniation. J Neurosurg 43:727-31.

7. Rohde V, Meyer B, Schaller C, Hassler WE (1998) Spondylodiscitis after lumbar discectomy. Incidence and a proposal for prophylaxis. Spine (Phila Pa 1976) 23:61520.

8. Carreon LY, Puno RM, Dimar JR, 2nd, Glassman SD, Johnson JR (2003) Perioperative complications of posterior lumbar decompression and arthrodesis in older adults. J Bone Joint Surg Am 85-A:2089-92.

9. Rechtine GR, Bono PL, Cahill D, Bolesta MJ, Chrin AM (2001) Postoperative wound infection after instrumentation of thoracic and lumbar fractures. J Orthop Trauma $15: 566-9$.

10. Carreon LY, Puno RM, Lenke LG, Richards BS, Sucato DJ, Emans JB, Erickson MA (2007) Non-neurologic complications following surgery for adolescent idiopathic scoliosis. J Bone Joint Surg Am 89:2427-32.

11. Coe JD, Arlet V, Donaldson W, Berven S, Hanson DS, Mudiyam R, Perra JH, Shaffrey CI (2006) Complications in spinal fusion for adolescent idiopathic scoliosis in the new millennium. A report of the Scoliosis Research Society Morbidity and Mortality Committee. Spine (Phila Pa 1976) 31:345-9.

12. Grosman R, Vlach O, Leznar M (2002) [Infections in surgery of idiopathic scoliosis]. Acta Chir Orthop Traumatol Cech 69:175-8.

13. Hahn F, Zbinden R, Min K (2005) Late implant infections caused by Propionibacterium acnes in scoliosis surgery. Eur Spine J 14:783-8.

14. Ho C, Sucato DJ, Richards BS (2007) Risk factors for the development of delayed infections following posterior spinal fusion and instrumentation in adolescent idiopathic scoliosis patients. Spine (Phila Pa 1976) 32:2272-7. 
1 15. Rihn JA, Lee JY, Ward WT (2008) Infection after the surgical treatment of adolescent idiopathic scoliosis: evaluation of the diagnosis, treatment, and impact on clinical outcomes. Spine (Phila Pa 1976) 33:289-94.

16. Barker FG, 2nd (2002) Efficacy of prophylactic antibiotic therapy in spinal surgery: a meta-analysis. Neurosurgery 51:391-400; discussion -1.

17. Rubinstein E, Findler G, Amit P, Shaked I (1994) Perioperative prophylactic cephazolin in spinal surgery. A double-blind placebo-controlled trial. J Bone Joint Surg Br 76:99-102.

18. Savitz MH, Malis LI, Savitz SI (2003) Efficacy of prophylactic antibiotic therapy in spinal surgery: a meta-analysis. Neurosurgery 53:243-4; author reply 4-5.

19. Nohara Y, Taneichi H, Ueyama K, Kawahara N, Shiba K, Tokuhashi Y, Tani T, Nakahara S, Iida T (2004) Nationwide survey on complications of spine surgery in Japan. J Orthop Sci 9:424-33.

20. Takahashi H, Wada A, Iida Y, Yokoyama Y, Katori S, Hasegawa K, Shintaro T, Suguro T (2009) Antimicrobial prophylaxis for spinal surgery. J Orthop Sci 14:40-4.

21. Page CP, Bohnen JM, Fletcher JR, McManus AT, Solomkin JS, Wittmann DH (1993) Antimicrobial prophylaxis for surgical wounds. Guidelines for clinical care. Arch Surg 128:79-88.

22. Petignat C, Francioli P, Harbarth S, Regli L, Porchet F, Reverdin A, Rilliet B, de Tribolet N, Pannatier A, Pittet D, Zanetti G (2008) Cefuroxime prophylaxis is effective in noninstrumented spine surgery: a double-blind, placebo-controlled study. Spine (Phila Pa 1976) 33:1919-24.

23. Rimoldi RL, Haye W (1996) The use of antibiotics for wound prophylaxis in spinal surgery. Orthop Clin North Am 27:47-52. 
1 24. Sanderson PJ (1993) Antimicrobial prophylaxis in surgery: microbiological factors. J Antimicrob Chemother 31 Suppl B:1-9.

25. Mangram AJ, Horan TC, Pearson ML, Silver LC, Jarvis WR (1999) Guideline for Prevention of Surgical Site Infection, 1999. Centers for Disease Control and Prevention (CDC) Hospital Infection Control Practices Advisory Committee. Am J Infect Control 27:97-132; quiz 3-4; discussion 96.

26. Kanayama M, Hashimoto T, Shigenobu K, Oha F, Togawa D (2007) Effective prevention of surgical site infection using a Centers for Disease Control and Prevention guideline-based antimicrobial prophylaxis in lumbar spine surgery. J Neurosurg Spine 6:327-9.

27. Kernodle DS, Classen DC, Burke JP, Kaiser AB (1990) Failure of cephalosporins to prevent Staphylococcus aureus surgical wound infections. JAMA 263:961-6.

28. Kakimaru H, Kono M, Matsusaki M, Iwata A, Uchio Y (2010) Postoperative antimicrobial prophylaxis following spinal decompression surgery: is it necessary? J Orthop Sci 15:305-9.

29. Olsen MA, Nepple JJ, Riew KD, Lenke LG, Bridwell KH, Mayfield J, Fraser VJ (2008) Risk factors for surgical site infection following orthopaedic spinal operations. J Bone Joint Surg Am 90:62-9.

30. Richards BS (1995) Delayed infections following posterior spinal instrumentation for the treatment of idiopathic scoliosis. J Bone Joint Surg Am 77:524-9.

31. Dobzyniak MA, Fischgrund JS, Hankins S, Herkowitz HN (2003) Single versus multiple dose antibiotic prophylaxis in lumbar disc surgery. Spine (Phila Pa 1976) 28:E453-5.

32. Dimick JB, Lipsett PA, Kostuik JP (2000) Spine update: antimicrobial prophylaxis in spine surgery: basic principles and recent advances. Spine (Phila Pa 1976) 25:2544-8. 
1 33. Cahill PJ, Warnick DE, Lee MJ, Gaughan J, Vogel LE, Hammerberg KW, Sturm PF (2010) Infection after spinal fusion for pediatric spinal deformity: thirty years of experience at a single institution. Spine (Phila Pa 1976) 35:1211-7.

34. Savitz SI, Lee LV, Goldstein HB, Savitz MH (1994) Investigations of the bacteriologic factors in cervical disk surgery. Mt Sinai J Med 61:272-5.

35. Tronnier V, Schneider R, Kunz U, Albert F, Oldenkott P (1992) Postoperative spondylodiscitis: results of a prospective study about the aetiology of spondylodiscitis after operation for lumbar disc herniation. Acta Neurochir (Wien) 117:149-52.

36. Weinstein MA, McCabe JP, Cammisa FP, Jr. (2000) Postoperative spinal wound infection: a review of 2,391 consecutive index procedures. J Spinal Disord 13:422-6.

37. Nichols RL (1995) Surgical antibiotic prophylaxis. Med Clin North Am 79:509-22.

38. DiPiro JT, Bowden TA, Jr., Hooks VH, 3rd (1984) Prophylactic parenteral cephalosporins in surgery. Are the newer agents better? JAMA 252:3277-9.

39. Oishi CS, Carrion WV, Hoaglund FT (1993) Use of parenteral prophylactic antibiotics in clean orthopaedic surgery. A review of the literature. Clin Orthop Relat Res 249-55.

40. Hellbusch LC, Helzer-Julin M, Doran SE, Leibrock LG, Long DJ, Puccioni MJ, Thorell WE, Treves JS (2008) Single-dose vs multiple-dose antibiotic prophylaxis in instrumented lumbar fusion--a prospective study. Surg Neurol 70:622-7; discussion 7.

41. Shaffer WO, Baisden, J., Fernand, R., Matz, P. (2013) Antibiotic Prophylaxis in Spine Surgery. NASS Clinical Guidelines. 
Table 1: Comparison of pre-operative, Intra-operative and post-operative variables between the two groups

\begin{tabular}{|c|c|c|c|}
\hline Variable & $\begin{array}{l}\text { Group A (n=155); } \\
\text { Mean (SD; range) }\end{array}$ & $\begin{array}{l}\text { Group B }(\mathrm{n}=71) \\
\text { Mean (SD; range) }\end{array}$ & P-value \\
\hline Age (years) & $\begin{array}{l}15.03 \text { (SD 2.642; 10- } \\
27)\end{array}$ & $\begin{array}{l}15.11 \\
11-25)\end{array}$ (SD 2.72; & 0.833 \\
\hline Sex (Female/Male) & $132 / 23$ & $60 / 11$ & 0.899 \\
\hline $\begin{array}{lll}\begin{array}{l}\text { Body } \\
\text { (BMI) }\end{array} & \text { mass } & \text { index } \\
\end{array}$ & $\begin{array}{l}18.3 \text { (SD 2.5; 13.52- } \\
27.28)\end{array}$ & $\begin{array}{l}18.73 \text { (SD } \\
11.29-31.49)\end{array}$ & 0.297 \\
\hline Smoking (patients) & 3 & 2 & 0.677 \\
\hline $\begin{array}{l}\text { Pre-operative } \\
\text { Haemoglobin (g/dL) }\end{array}$ & $\begin{array}{l}\text { 13.13 (SD 1.46; 9.8- } \\
12.9)\end{array}$ & $\begin{array}{l}11.76 \quad \text { (SD } 1.65 ; \\
9.3-16.4)\end{array}$ & 0.228 \\
\hline $\begin{array}{l}\text { Pre-operative } \\
\text { protein }(\mathrm{g} / \mathrm{L})\end{array}$ & $\begin{array}{l}75.15 \text { (SD 6.54; 42- } \\
89)\end{array}$ & $\begin{array}{l}75.52 \\
47-87)\end{array}$ (SD 6.70; & 0.699 \\
\hline $\begin{array}{l}\text { Pre-operative albumin } \\
\text { (g/L) }\end{array}$ & $\begin{array}{l}44.33 \text { (SD 4.66; 17- } \\
52 \text { ) }\end{array}$ & $\begin{array}{l}43.01 \\
22-55)\end{array}$ (SD 5.41; & 0.063 \\
\hline $\begin{array}{l}\text { Pre-operative globulin } \\
\text { (g/L) }\end{array}$ & $\begin{array}{l}30.80 \text { (SD 3.78; 22- } \\
41)\end{array}$ & $\begin{array}{l}32.55 \\
25-40)\end{array}$ (SD $3.17 ;$ & $<0.001$ \\
\hline $\begin{array}{l}\text { Scoliosis curve type } \\
\text { (MT/DM/DT/TM/TL) }\end{array}$ & $108 / 25 / 19 / 0 / 3$ & $42 / 18 / 8 / 2 / 1$ & 0.277 \\
\hline $\begin{array}{l}\text { Mean number of levels } \\
\text { fused per patient }\end{array}$ & 9.26 (SD 2.06; 6-13) & 9.8 (SD 2.23; 6-15) & 0.770 \\
\hline $\begin{array}{ll}\begin{array}{l}\text { Surgical } \\
\text { (minutes) }\end{array} & \text { duration } \\
\end{array}$ & $\begin{array}{l}283.91 \text { (SD 64.85; } \\
\text { 188-480) }\end{array}$ & $\begin{array}{l}277.94 \text { (SD } 70.7 ; \\
192-430)\end{array}$ & 0.533 \\
\hline $\begin{array}{lcr}\text { Mean } & \text { number } & \text { of } \\
\text { anchor } & \text { points } & \text { per } \\
\text { patient } & & \end{array}$ & 10.9 (SD 2.89; 6-21) & $\begin{array}{l}9.28 \\
17)\end{array} \quad$ SD 2.12;7- & $<0.001$ \\
\hline $\begin{array}{l}\text { Intra-operative blood } \\
\text { loss (ml) }\end{array}$ & $\begin{array}{l}796.29 \text { (SD 391.83; } \\
\text { 250-2200) }\end{array}$ & $\begin{array}{l}\text { 638.56 (SD 406.33; } \\
150-1850)\end{array}$ & 0.006 \\
\hline $\begin{array}{l}\text { Intra-operative } \\
\text { transfusion (ml) }\end{array}$ & $\begin{array}{l}\text { Blood: } 402.94 \text { (SD } \\
270.361 ; 0-1400) \\
\text { FFP: 248.01 (SD } \\
210.30 ; 0-785)\end{array}$ & $\begin{array}{l}\text { Blood: } 442.96 \text { (SD } \\
\text { 322.68; } 0-1445) \\
\text { FFP: 402.07 (SD } \\
\text { 301.15; } 0-1000)\end{array}$ & 0.150 \\
\hline
\end{tabular}




\begin{tabular}{|l|l|l|l|l|}
\hline $\begin{array}{l}\text { Post-operative } \\
\text { transfusion (ml) }\end{array}$ & $\begin{array}{l}\text { Blood: 191.25 } \\
\text { 198.80; 0-785) }\end{array}$ & $\begin{array}{l}\text { Blood: 267.68 (SD } \\
\text { 292.43; 0-1250) }\end{array}$ & 0.241 \\
$\begin{array}{l}\text { FFP: 23.32 } \\
76.88 ; 0-570)\end{array}$ & (SD & $\begin{array}{l}\text { FFP: 12.48 (SD } \\
75.47 ; 0-536)\end{array}$ & \\
\hline $\begin{array}{l}\text { Post-operative drain } \\
\text { (spine) (ml) }\end{array}$ & $\begin{array}{l}\text { Total drain: 228.01 } \\
\text { (SD 231.78; 5-1510) }\end{array}$ & $\begin{array}{l}\text { Total drain: 473.01 } \\
\text { (SD 365.98; 5- } \\
\text { 1740) }\end{array}$ & 0.01 \\
\hline $\begin{array}{l}\text { Post-operative duration } \\
\text { of drain in-situ (days) }\end{array}$ & 3.1 (SD 0.65; 2-6) & 3.2 (SD 0.72; 2-7) & 0.356 \\
\hline
\end{tabular}

Group A: Two doses of postoperative antimicrobials; Group B: Antimicrobials till drain removal *MT- Main thoracic, DM-double major, DT- double thoracic, TM- triple major, TLthoracolumbar, SD-standard deviation, FFP- fresh frozen plasma 